\title{
Numerical Prediction and Experimental Investigation of Residual Stresses in Sequential Milling of GH4169 Considering Initial Stress Effect
}

\section{Gonghou Yao}

Shandong University

Zhanqiang Liu ( $\square$ melius@sdu.edu.cn )

Shandong University https://orcid.org/0000-0003-3662-7625

Qinghua Song

Shandong University

Bing Wang

Shandong University

Yukui Cai

Shandong University

\section{Research Article}

Keywords: sequential milling, residual stress, finite element modelling, initial stress

Posted Date: July 20th, 2021

DOI: https://doi.org/10.21203/rs.3.rs-717752/v1

License: (c) (1) This work is licensed under a Creative Commons Attribution 4.0 International License. Read Full License

Version of Record: A version of this preprint was published at The International Journal of Advanced Manufacturing Technology on January 24th, 2022. See the published version at https://doi.org/10.1007/s00170-022-08740-0. 


\title{
Numerical Prediction and Experimental Investigation of Residual Stresses in Sequential Milling of GH4169 Considering Initial Stress Effect
}

\author{
Gonghou Yao ${ }^{\text {a,b }}$, Zhanqiang Liu ${ }^{\text {a,b, }}$, Qinghua Song ${ }^{1,2}$, Bing Wang ${ }^{1,2}$, Yukui Cai ${ }^{1,2}$ \\ $\left({ }^{1}\right.$ School of Mechanical Engineering, Shandong University, China; \\ ${ }^{2}$ Key National Demonstration Center for Experimental Mechanical Engineering Education/Key Laboratory of \\ High Efficiency and Clean Mechanical Manufacture of MQE, China) \\ *Corresponding author, Email: melius@sdu.edu.cn, Postal address: School of Mechanical Engineering, Shandong \\ University, Jingshi Road 17923, Jinan 250061, P.R. China. Telephone: +86-531-88393206, Fax: +86-531- \\ 88393206.
}

\begin{abstract}
Residual stresses affect the service life and causes the deformation of machined parts. Therefore, the study on development of residual stresses during machining operation is very important. For this, an analytical and numerical models have been developed to predict the residual stresses for single-step machining operation. However, the parts are usually machined with a serial of production processes. A numerical model for predicting residual stress in sequential side milling GH4169 considering initial stress was proposed in this research. The initial residual stress distribution due to previous-step milling was considered in the proposed model. It was assumed that this initial residual stress value changed with the depth from the machined surface, while the residual stress on the identical horizontal plane was assumed with uniform distribution. The proposed numerical simulation model could predict the stress value of the machined surface, the stress value of the compression valley and the residual stress distribution in the depth direction beneath the machined surface with high accuracy. Experimental investigations of sequential side milling GH4169 were conducted and the generated residual stresses were measured. The distribution trend and influence rule of residual stress between two sequential milling steps were analyzed. The residual stress distribution beneath the surface showed a spoon-shaped pattern. The thickness of the residual stress influence layer (RSIL) after the current milling step was affected by the depth of cut and the RSIL thickness of the previous milling step. The numerical model could predict the thickness of RSIL and optimize the depth of cut in sequential side milling.
\end{abstract}

Keywords: sequential milling, residual stress, finite element modelling, initial stress

\section{Introduction}


Superalloy GH4169 has been widely used in the aerospace field due to its excellent hightemperature strength, heat corrosion resistance, high-temperature oxidation resistance, and fatigue resistance [1,2]. High surface quality is required for aerospace components manufactured by side milling GH4169. Residual stress is one of the important indicators that justifies the quality of machined surface $[3,4]$. The residual stress affects the service life and causes the deformation of machined parts $[5,6]$.

In the past few decades, the researches on residual stress caused by machining mainly focused on the influence of tool parameters and machining parameters in single-step machining. However, the parts are usually finished with multi-step machining processes. Several researchers have studied the influence of residual stresses between serial steps.

Karabelchtchikova et al. [7] carried out an experimental research of the residual stress in multipass grinding. This research mainly studied the residual stress distribution in heat treatment and subsequent multi-pass grinding. The results showed a non-linear superposition relationship in the residual stress distribution between each process step.

Dehmani et al. [8] developed a multi-steps finite element model for orthogonal cutting. The influence of cumulated strain and heat induced by the different steps on the prediction of residual stress distribution were simulated. The distribution of the residual stress in depth simulated with proposed model was consistent with that by experiment measured. The results showed that the multisteps model could provide better results for the prediction of residual stress than a single-step model did. However, the initial stress effect was neglected with the develop model.

Grochała et al. [9] conducted a study on the residual stress of the burnished surface. A burnishing FEM model of the surface with the milling track was developed. It was found that the stress value after burnishing was significantly affected by the change of surface roughness. The distribution depth of the maximum compressive residual stress after burnishing decreased with the increase of the initial roughness of the milled surface.

Fergani et al. [10] proposed an analytical model for the prediction of residual stress in the multisteps milling. The authors claimed that the proposed analytical model could predict the residual stress value after each step. However, the residual stress prediction accuracy of this model was affected by the over-simplification of the model assumptions.

Ma et al. [11] conducted an experimental research to study the evolution of the residual stress field during multi-steps face milling. It was found that the surface residual stress was mainly 
determined by the final processing step. The residual stress distribution in depth depended on the superposition of the processing history.

Singla et al. [12] conducted a numerical study of the residual stress in the two-steps turning process. A numerical simulation model of two-steps turning was developed. The surface after twostep turning could be obtained by the design of a double-edged turning tool in sole one-step cutting.The initial residual stress effect was neglected in the numerical simulation model of two-step turning.

The residual stresses could accumulate and redistribute between serial steps or processes. However, the effects of the initial stress generated in the previous machining step on the residual stress in current machining step are seldom considered in these developed models, which makes it hard to attain satisfied prediction accuracy of the final residual stress distribution in the machined surface. A numerical model for predicting machined surface residual stress in sequential side milling GH4169 considering initial stress will be proposed in this research. The initial residual stress distribution due to previous-step milling is considered in the proposed model. The experimental investigations of sequential side milling GH4169 are conducted to verify the model prediction results.

\section{Theoretical research}

\subsection{Conversion equation from milling to equivalent orthogonal cutting}

Effective conversion from three-dimensional (3D) side milling to two-dimensional (2D) orthogonal turning makes it easier to import the initial residual stress into the simulation model [13]. Fig. 1 shows the process of converting 3D side milling to 2D orthogonal turning.
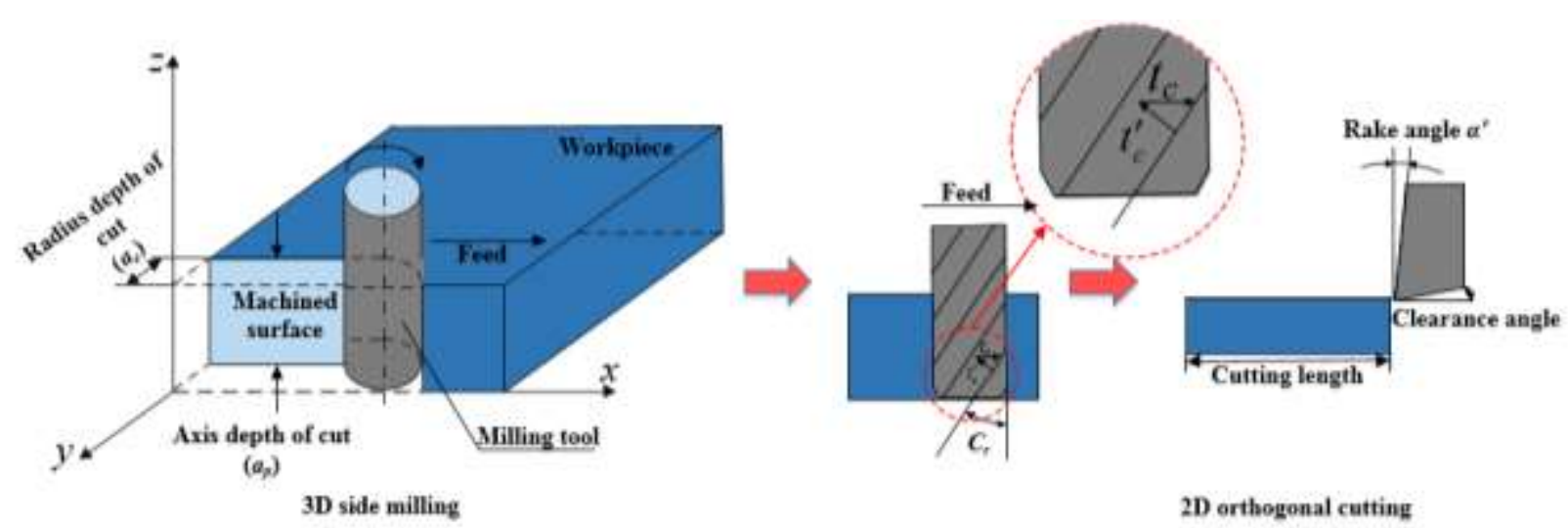

Fig. 1. The process of converting 3D side milling into $2 \mathrm{D}$ orthogonal turning.

Due to the geometry of the milling tool, the chips generated during milling cannot remain the same thickness. Therefore, the equivalent depth of cut changes with the rotation angle in the 
orthogonal model. The average depth of cut is defined as,

$$
\overline{t_{c}}=\frac{1}{2} \frac{V_{f}}{R P M}
$$

Where $\overline{t_{c}}$ is the average depth of cut, $V_{f}$ is the feed rate, and RPM is the spindle speed, the instant equivalent cutting depth is,

$$
t_{c}(\phi)=\sqrt{2} \times \bar{t}_{c} \times \sin (\phi)
$$

Where $\phi=2 \pi \times R P M \times t$ is the rotation angle, $t$ is the cutting time. The equivalent side cutting edge angle $C_{r}^{\prime}$ is,

$$
C_{r}^{\prime}=C_{r}+\lambda
$$

Where $C_{r}$ is the side cutting edge angle, and $\lambda$ is the chip flow angle. The equivalent chip flow angle $\lambda^{\prime}$ is given by the equivalent inclination angle $s^{\prime}$,

$$
\lambda^{\prime}=s^{\prime}=\arcsin \left(\cos \lambda_{0} \sin s-\sin \lambda_{0} \cos s\right)
$$

Where $s$ is the inclination angle, $\alpha$ is the rake angle, and $\lambda_{0}$ is defined as,

$$
\lambda_{0}=\arccos \left(\frac{\sec s-\tan s \tan \lambda \tan \alpha}{\sqrt{(\tan s-\tan \lambda \tan \alpha \sec s)^{2}+\sec ^{2} \lambda}}\right)
$$

The equivalent rake angle is,

$$
\alpha^{\prime}=\arcsin \left(\frac{\sec \lambda_{0} \sin s-\sin s^{\prime}}{\tan \lambda_{0} \cos s^{\prime}}\right)
$$

The equivalent cutting depth is,

$$
t_{c}^{\prime}=t_{c}(\phi) \times \cos C_{r}^{\prime}
$$

The equivalent cutting speed is,

$$
V(\phi)=\sqrt{V_{f}^{2}+V_{r}^{2}+2 V_{f} V_{r} \cos \phi}
$$

Where $V_{r}=2 \pi R \times R P M$ is the rotation speed and $R$ is the tool radius.

\subsection{Modification equation of measured residual stress in depth}

The workpiece is stripped due to the measurement of residual stress in depth. The surface stress will be redistributed after the delamination. Therefore, the residual stress measured at a point on the surface is not the value at the same depth before the delamination. The measured value need be 
corrected to obtain the accurate residual stress distribution in the depth direction of the workpiece.

Since the thickness of the milling layer is much smaller than the length and width of the workpiece, the blocky workpiece in this paper can approximate a flat plate. It was assumed that the residual stress value changed with the depth from the machined surface, while the residual stress on the identical horizontal plane was assumed with uniform distribution. The residual stress is assumed to distribute symmetrically along the center plane of the plate .At the same time, the residual stress is parallel to the center plane of the plate. As shown in Fig. 2, if the length and width of the plate are much greater than the thickness, the plate can be regarded as an infinite surface when the residual stress in the center of the plate is measured. The plate is peeled from the bottom surface at point 0 . It is assumed that the accurate stress is $\sigma_{x x}(z)$ and $\sigma_{y y}(z)$ when the layer is peeled to the depth $z$. The measured stress is $\sigma_{x x}^{\prime}(z)$ and $\sigma_{y y}^{\prime}(z)$. The stress release after peeling are $\Delta \sigma_{x x}(z)$ and $\Delta \sigma_{y y}(z)$

$$
\begin{aligned}
& \Delta \sigma_{x x}(z)=\frac{1}{h-z} \int_{0}^{z} \sigma_{x x}(\zeta) d \zeta \\
& \Delta \sigma_{y y}(z)=\frac{1}{h-z} \int_{0}^{z} \sigma_{y y}(\zeta) d \zeta
\end{aligned}
$$

Since the peeling is performed on one side, the bending moments $M_{x}$ and $M_{y}$ are added to the plate .The bending moments cause additional stresses $\Delta \sigma_{M x}(z)$ and $\Delta \sigma_{M y}(z)$,

$$
\begin{aligned}
& M_{x}(z)=-\int_{0}^{z} \frac{1}{2}(h-\zeta) \sigma_{x x}(\zeta) d \zeta \\
& M_{y}(z)=-\int_{0}^{z} \frac{1}{2}(h-\zeta) \sigma_{y y}(\zeta) d \zeta \\
& \Delta \sigma_{M x}(z)=-\frac{6}{(h-z)^{2}} \int_{0}^{z} \frac{1}{2}(h-\zeta) \sigma_{x x}(\zeta) d \zeta \\
& \Delta \sigma_{M y}(z)=-\frac{6}{(h-z)^{2}} \int_{0}^{z} \frac{1}{2}(h-\zeta) \sigma_{y y}(\zeta) d \zeta
\end{aligned}
$$

Moreover,

$$
\begin{aligned}
& \sigma_{x x}=\sigma_{x x}^{\prime}+\Delta \sigma_{x x}+\Delta \sigma_{M x} \\
& \sigma_{y y}=\sigma_{y y}^{\prime}+\Delta \sigma_{y y}+\Delta \sigma_{M y}
\end{aligned}
$$

By substituting Eqs. (9 to (14) into Eqs. (15) and (16), and replacing $\sigma^{\prime}$ with $\sigma$ for the convenience of calculation, $\sigma_{x x}(z)$ and $\sigma_{y y}(z)$ can be calculated, 


$$
\begin{aligned}
& \sigma_{x x}(z)=\sigma_{x x}^{\prime}(z)+\frac{1}{h-z} \int_{0}^{z} \sigma_{x x}^{\prime}(\zeta) d \zeta-\frac{6}{(h-z)^{2}} \int_{0}^{z} \frac{1}{2}(h-\zeta) \sigma_{x x}^{\prime}(\zeta) d \zeta \\
& \sigma_{y y}(z)=\sigma_{y y}^{\prime}(z)+\frac{1}{h-z} \int_{0}^{z} \sigma_{y y}^{\prime}(\zeta) d \zeta-\frac{6}{(h-z)^{2}} \int_{0}^{z} \frac{1}{2}(h-\zeta) \sigma_{y y}^{\prime}(\zeta) d \zeta
\end{aligned}
$$

In this paper, $\sigma_{x x}(z)$ and $\sigma_{y y}(z)$ in Eqs. (17) and (18) are taken as the residual stress values in the depth direction of the workpiece to ensure the accuracy of the experimental data.

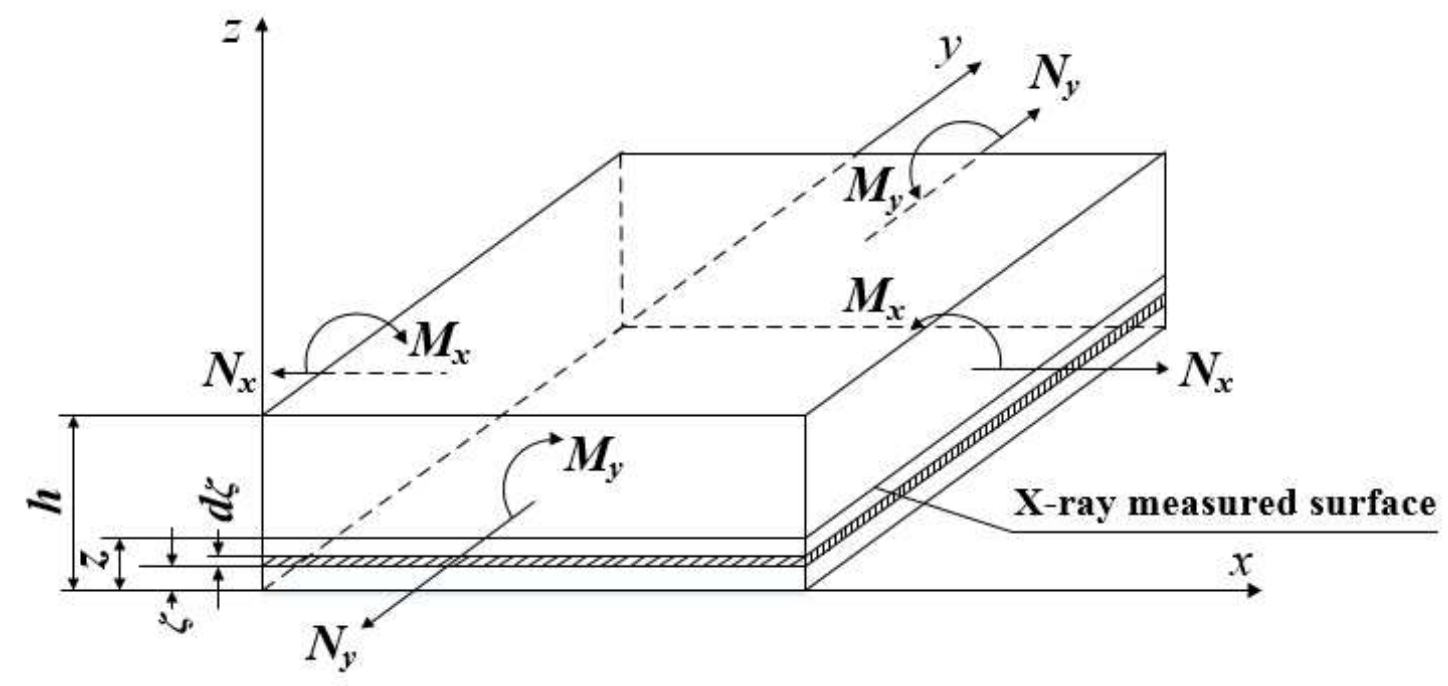

Fig. 2. Residual stress correction of peeling plate.

\section{Finite element simulation of sequential side milling GH4169}

\subsection{Geometry modeling and mesh controlling}

The metal cutting finite element simulation software AdvantEdge FEM was used to construct the two-dimensional orthogonal cutting simulation. The workpiece was a rectangle with a length of $5 \mathrm{~mm}$ and a height of $2 \mathrm{~mm}$. The tool length and width were both $1.5 \mathrm{~mm}$. The cutting edge radius of the tool was $0.04 \mathrm{~mm}$, the rake angle was $13.8^{\circ}$, and the clearance angle was $10^{\circ}$.

In the simulation, the workpiece material was nickel-base superalloy GH4169. The JohnsonCook constitutive model (Eq. 19) was used in the simulation.

$$
\sigma=\left(A+B \bar{\varepsilon}^{n}\right)\left[1+C \ln \left(\frac{\&}{\mathcal{E}}\right)\right]\left[1-\left(\frac{T-T_{r}}{T_{m}-T_{r}}\right)^{m}\right]
$$

Where $A, B, C, m, n$ are the material constants, $A$ is the yield stress, $B$ is the hardening modulus, $C$ is the strain rate dependency coefficient, $m$ is the thermal softening coefficient, and $n$ is the strain hardening coefficient. $\bar{\varepsilon}$ is equivalent strain, \& is equivalent strain rate, and $\mathcal{E}_{i}$ is the reference strain 
rate. $T$ is the overall temperature of the workpiece, $T_{m}$ is the melting temperature of GH4169, and $T_{r}$ is room temperature.

Table 1 shows the Johnson-Cook parameters of GH4169. The physical and mechanical properties of the tool and workpiece material are specified in Table 2. The tool material was made of cemented carbide with two layers of TiN coating, and the thickness was $0.003 \mathrm{~mm}$ and $0.001 \mathrm{~mm}$ respectively.

Table 1. Johnson-Cook constitutive model parameters of GH4169 [14].

\begin{tabular}{ccccc}
\hline$A(\mathrm{MPa})$ & $B(\mathrm{MPa})$ & $C$ & $n$ & $m$ \\
\hline 450 & 17000 & 0.017 & 0.65 & 1.3 \\
\hline
\end{tabular}

Table 2. The physical and mechanical properties of the tool and workpiece material [14].

\begin{tabular}{ccccccc}
\hline Properties & Density & $\begin{array}{c}\text { Young's } \\
\text { Modulus }\end{array}$ & $\begin{array}{c}\text { Poisson's } \\
\text { Ratio }\end{array}$ & $\begin{array}{c}\text { Thermal } \\
\text { Expansion }\end{array}$ & Conductivity & $\begin{array}{c}\text { Specific } \\
\text { Heat }\end{array}$ \\
\hline Tool & $14,800 \mathrm{Kg} / \mathrm{m}^{3}$ & $640 \mathrm{Gpa}$ & 0.22 & $4.5 \mu \mathrm{m} / \mathrm{mK}$ & $50.24 \mathrm{~W} / \mathrm{mK}$ & $220 \mathrm{~J} / \mathrm{kgK}$ \\
\hline Workpiece & $8250 \mathrm{Kg} / \mathrm{m}^{3}$ & $214580 \mathrm{Gpa}$ & 0.305 & $14.8 \mu \mathrm{m} / \mathrm{mK}$ & $17.8 \mathrm{~W} / \mathrm{mK}$ & $526.3 \mathrm{~J} / \mathrm{kgK}$ \\
\hline
\end{tabular}

The mesh of the simulation model was divided by the Lagrange method. The finite element mesh deforms with the deformation of the workpiece. The adaptive mesh technology in AdvantEdge was fully utilized to improve the calculation accuracy. The mesh of the workpiece was constructed by triangular elements, and the mesh elements were adaptively divided. The closer to the contact surface between the tool and the workpiece, the smaller the element was. The maximum element size of the workpiece was $0.1 \mathrm{~mm}$, the minimum element size of the workpiece was $0.02 \mathrm{~mm}$, and the workpiece had a total of 30,000 nodes. The maximum tool element size was $0.1 \mathrm{~mm}$, and the minimum tool element size was $0.06 \mathrm{~mm}$. Chip separation criteria and adaptive mesh refinement were applied. In order to improve the prediction accuracy of the residual stress, the simulation refined the mesh of RSIL and performed the thermal and mechanical coupling calculations.

\subsection{Boundary conditions and initial conditions}

Fig. 3 shows the boundary constraints of the simulation model. Simulation constraints were imposed on the left and bottom edges of the workpiece in the horizontal and vertical directions. The initial temperature was the environment temperature of $25^{\circ} \mathrm{C}$. The friction between the workpiece and the rake face followed the Coulomb friction law. The friction coefficient was 0.3 [15]. The effect of the initial residual stress distribution was considered in this model. It was assumed that this initial residual stress value changed with the depth from the machined surface, while the residual stress on 
the identical horizontal plane was assumed with a uniform distribution. The residual stress distribution of the workpiece in depth $(0-100 \mu \mathrm{m})$ before milling was measured. Then the measured initial stress was imported into the simulation model. Fig. 4 shows the initial residual stress distribution of the workpiece in the simulation model. Subroutines and secondary cutting functions in AdvantEdge were used to implement the sequential milling process. Fig. 5 depicts the temperature and residual stress distribution in the simulation model of sequential side milling.

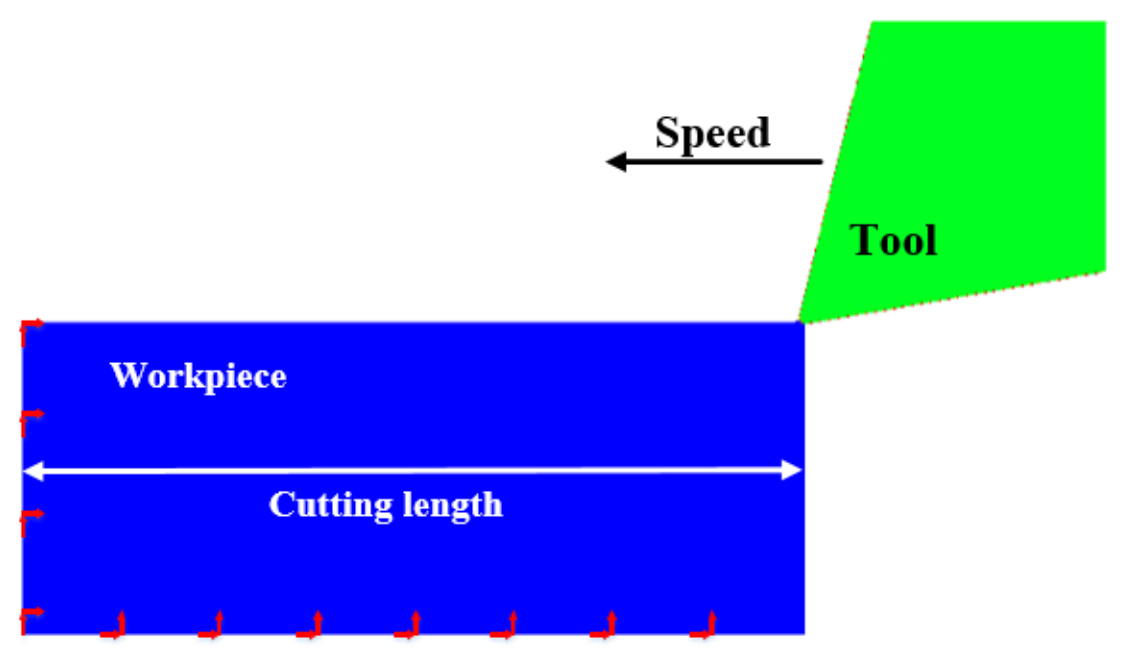

Fig. 3. Finite element simulation boundary conditions.
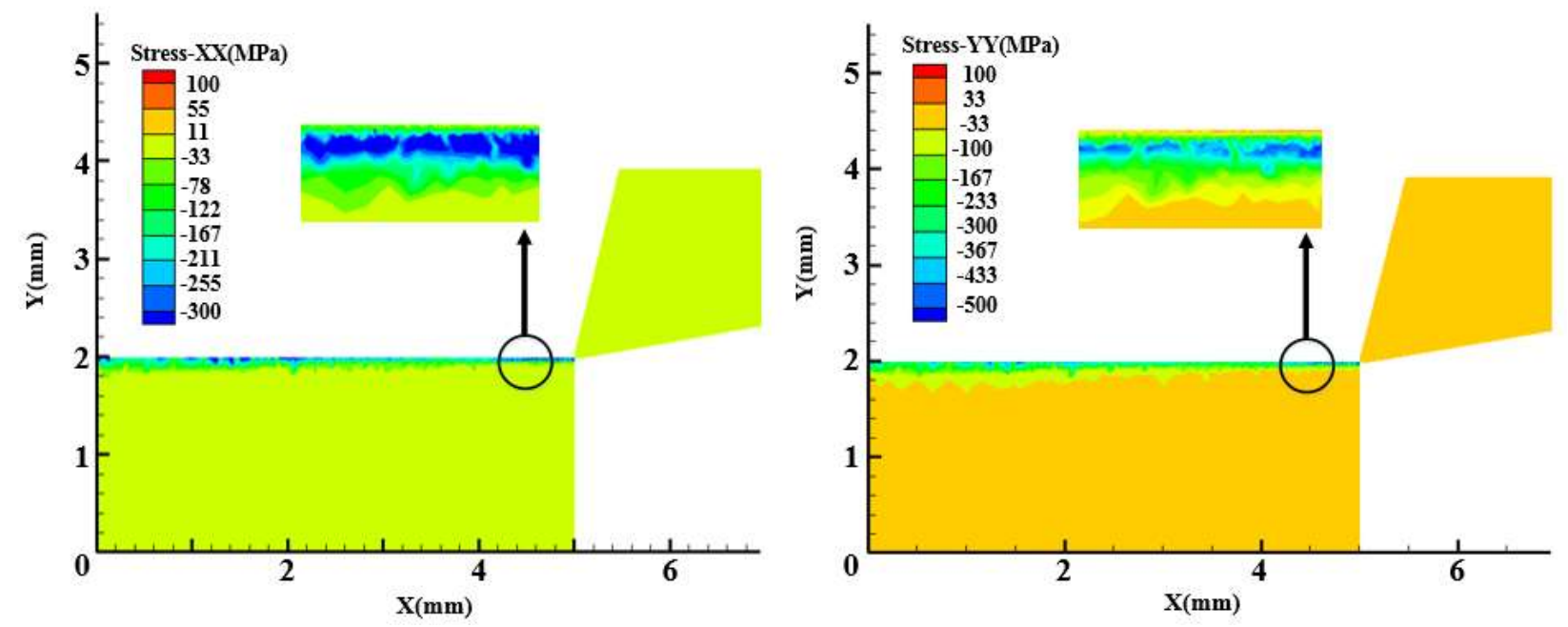

Fig. 4. Initial residual stress distribution in simulation model. 


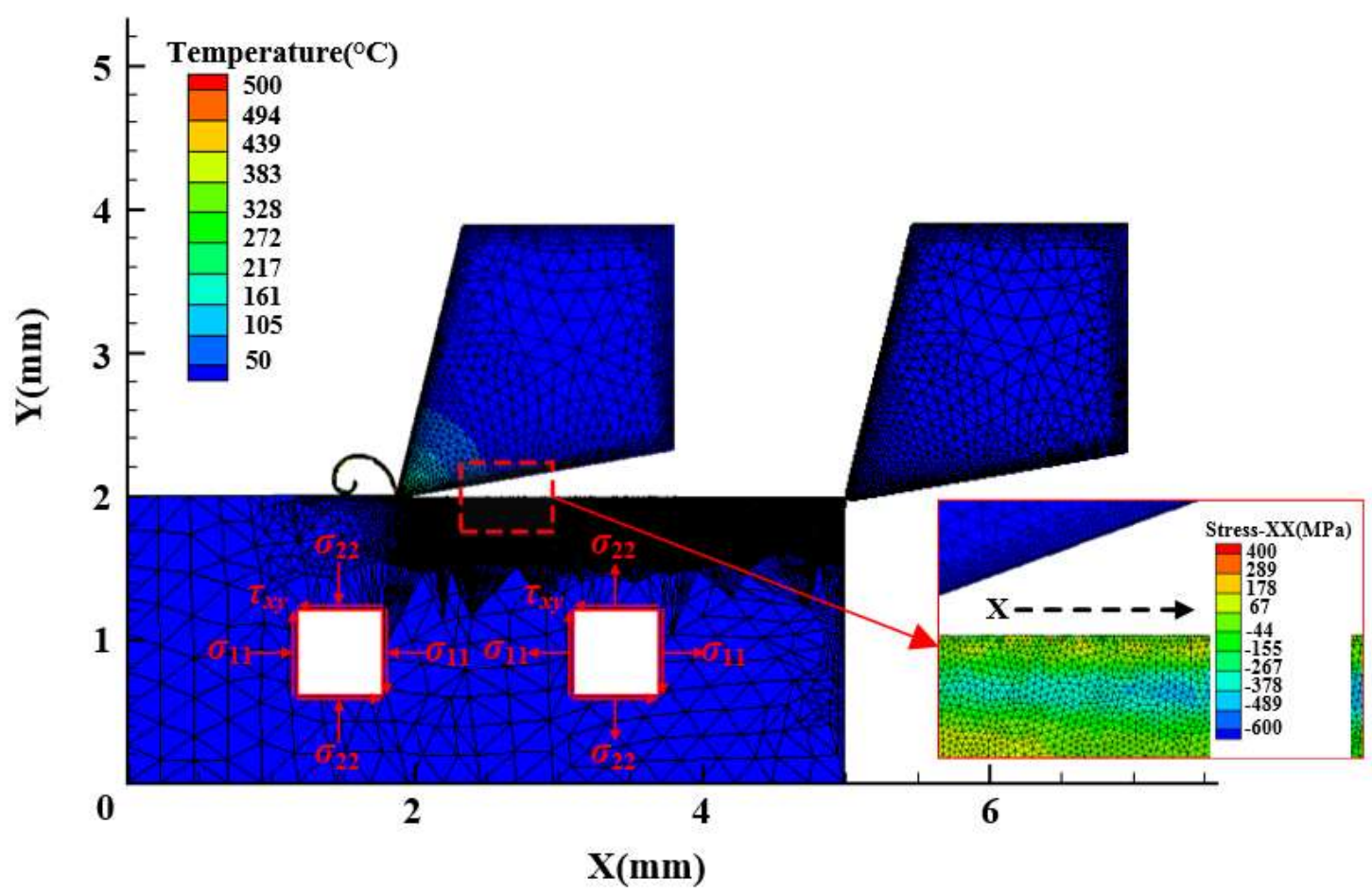

Fig. 5. Temperature and residual stress distribution in simulation model for sequential side milling.

\section{Sequential milling experiments and measurements of residual stress}

The material used in the experiment was GH4169. The metallographic structure of GH4169 is mainly composed of $\gamma$ matrix, dispersed-distributed strengthening phases $\gamma^{\prime}$ and $\gamma^{\prime \prime}, \delta$ phase, NbC, TiN, etc. The structure and chemical composition of its main constituent phases are shown in Table 3. The size of workpiece was $15 \mathrm{~mm} \times 10 \mathrm{~mm} \times 20 \mathrm{~mm}$. The workpiece was pretreated by electrical discharge machining (EDM) and heat treatment to eliminate part of the stress.

Table 3. The structure and chemical composition of GH4169 [16].

\begin{tabular}{ccccccccc}
\hline \multirow{2}{*}{ Phase } & Structure & \multicolumn{7}{c}{ Chemical composition (\%) } \\
\cline { 3 - 8 }$\gamma$ & $\mathrm{Al}(\mathrm{FCC})$ & 1.97 & 0.74 & 0.52 & 23.8 & 22 & 2.41 & 0.64 \\
$\gamma^{\prime}$ & $\begin{array}{c}\mathrm{Ll} \text { (FCC) } \\
\mathrm{Ni}_{3} \mathrm{Al}(\mathrm{Ti}, \mathrm{Nb})\end{array}$ & 10.2 & 8 & 9.4 & 2.15 & 0.5 & 0.4 & 0.35 \\
$\gamma^{\prime \prime}$ & $\begin{array}{c}\mathrm{DO}_{22}(\mathrm{BCC}) \\
\left(\mathrm{Ni}_{3} \mathrm{Nb}(\mathrm{Ti}, \mathrm{Al})\right.\end{array}$ & 25.1 & 0.44 & 4.92 & 0.86 & 0.76 & 1.05 & 0.01 \\
$\delta$ & $\mathrm{DOa}$ & 20.4 & 0.8 & 3.0 & 5.3 & 3.4 & 2.2 & 0.1 \\
\hline
\end{tabular}




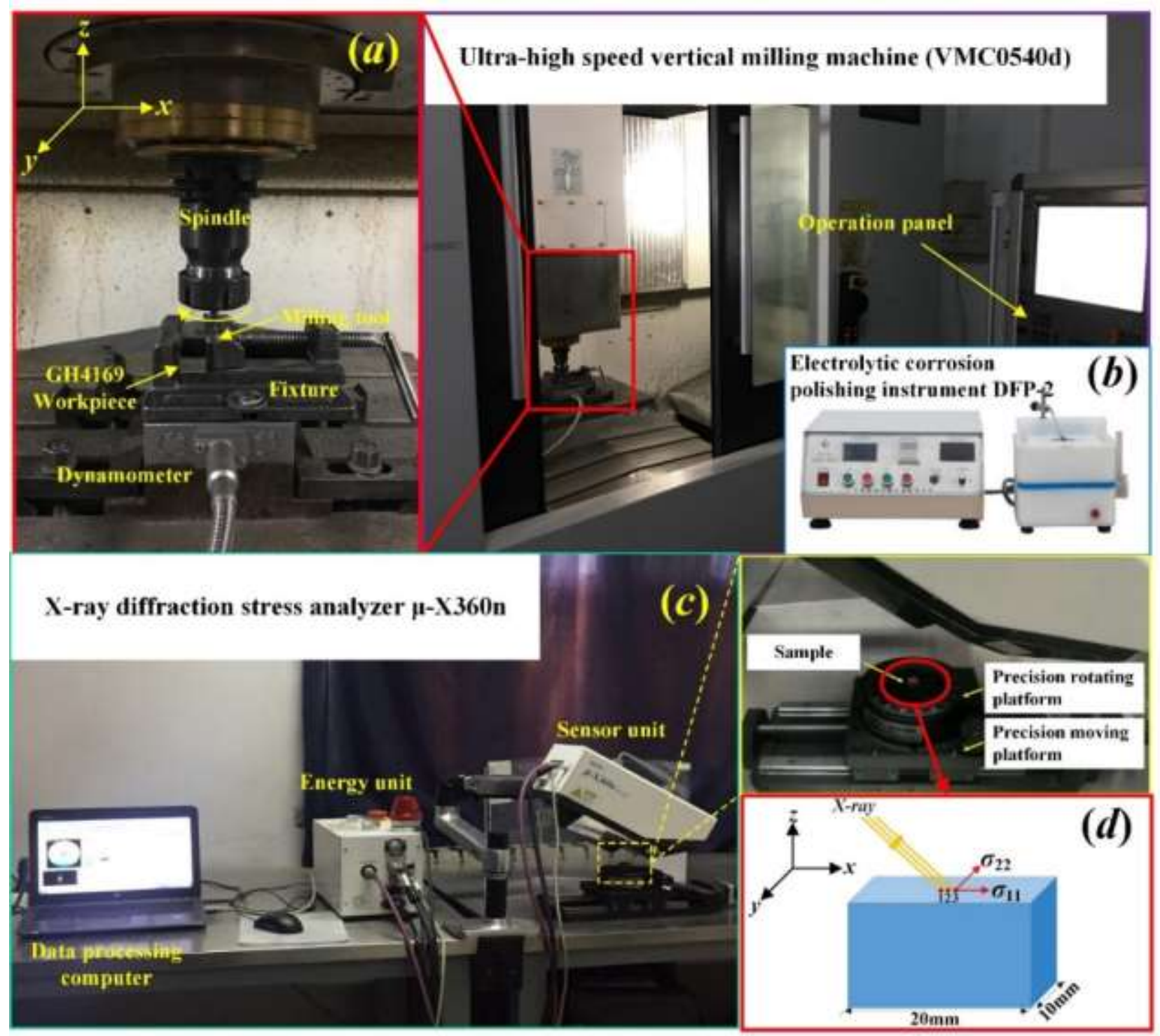

Fig. 6. Experimental and testing device (a) Side milling experimental platform (b) Electrolytic corrosion polishing instrument $(c)$ X-ray diffraction residual stress tester $(d)$ Residual stress test on the machined surface of the sample.

As shown in Fig. 6(a), the sequential side milling experiment was carried out on a vertical machining center (VMC0540d), and the Kistler-9257B three-way dynamic cutting dynamometer was used to record the milling force of each side milling step. Milling tools VSM-4E-D6.0 were cemented carbides with four-flute tool and AlTiN coating. During the experiments, the dry cutting was adopted in this study. The milling method was down milling due to the consideration of milling surface quality. Since the influence of tool wear on the residual stress was not considered in this paper, a new tool was used for each milling.

The most influential factor in milling was the depth of cut. Therefore, only radial depth of cut changed in sequential side milling. The sequential side milling experiment was divided into two steps 
in total. A total of four sets of sequential side milling GH4169 experiments were carried out. The experimental parameters of the first milling step were the same, radial depth of cut $a_{e}=0.3 \mathrm{~mm}$, feed per tooth $f=0.0075 \mathrm{~mm} / \mathrm{z}$, speed $v=38 \mathrm{~m} / \mathrm{min}$, axial depth of cut $a_{p}=8 \mathrm{~mm}$. The experiment kept the other parameters of the second milling step unchanged and only changed the radial depth of cut. The radial depth of cut $a_{e}$ was $0.02,0.05,0.1,0.3 \mathrm{~mm}$, respectively.

The workpiece material GH4169 is a polycrystalline material, X-ray diffraction method can be used to determine the residual stress. The X-ray diffraction phenomenon is shown in Fig. 7. X-ray diffraction satisfies the Bragg Eq. (20),

$2 d \sin \theta=n \lambda$

Where $\theta$ is the angle between the incident X-ray and the crystal plane, $d$ is the distance between the crystal planes, $\lambda$ is the X-ray wavelength, and $n$ is the diffraction index.

As shown in Fig. 7 when X-rays are diffracted, the angle between incident X-rays and diffracted $\mathrm{X}$-rays is $2 \theta$, which is called the diffraction angle. According to the Bragg equation, the interplanar crystal spacing $d$ can be obtained by measuring the diffraction angle. Therefore, the $\sin ^{2} \varphi$ method can be used to obtain the stress at any point and direction on the grain boundary plane $(h k l)$ in Eq. (21),

$$
\sigma_{p}=-\frac{E}{2(1+v)} \cot \theta_{0} \frac{\pi}{180}\left(\frac{\partial 2 \theta}{\partial \sin ^{2} \varphi}\right)
$$

Where $E$ is the elastic modulus, $v$ is the Poisson's ratio, $\varphi$ is the angle between the measured strain direction and the normal direction of the crystal plane, and $\theta_{0}$ is the diffraction half angle when $\varphi=0$, which is a stress-free state.

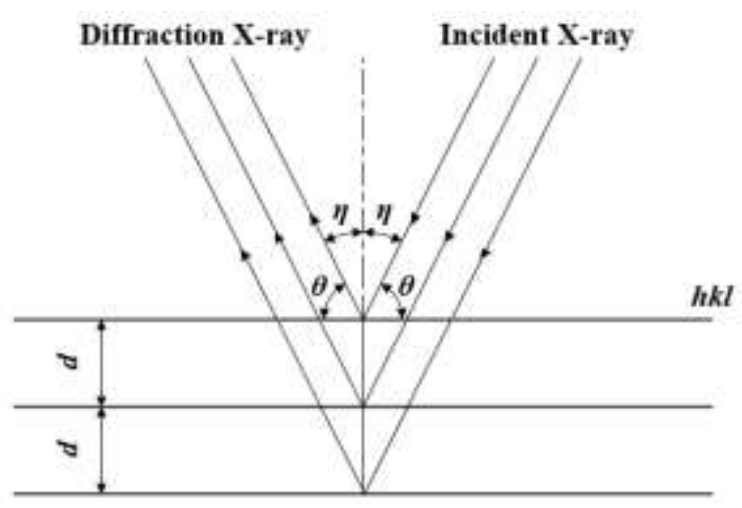

Fig. 7. X-ray diffraction of crystal plane.

As shown in Fig. 6(c), the X-ray diffraction stress analyzer $\mu$-X360n was used to measure the residual stress on the machined surface. The residual stress measurement position was selected at 3 points $(1,2,3)$ at the center of the machined surface for the measurement of the residual stress, as 
shown in Fig. $6(d)$. Residual stresses in the feed direction $\left(\sigma_{11}\right)$ and perpendicular to the feed direction $\left(\sigma_{22}\right)$ were measured respectively.In order to ensure the accuracy of the data, the average measured value of the three points was taken as the residual stress on the machined surface of each workpiece.

The main purpose of studying the residual stress was to improve the fatigue life of the workpiece. It was more important to study the distribution in depth of residual stress than to study that on the machining surface only. Due to the limitation of X-ray penetration depth $(10 \mu \mathrm{m})$, it was necessary to peel off the workpiece layer by layer before using X-ray diffraction for the measurement of residual stress. This paper used an electrolytic corrosion polishing process to peel off the workpiece surface. Residual stresses were measured at 8 positions in depth $(10 \mu \mathrm{m}, 20 \mu \mathrm{m}, 30 \mu \mathrm{m}, 40 \mu \mathrm{m}, 50 \mu \mathrm{m}, 60$ $\mu \mathrm{m}, 80 \mu \mathrm{m}, 100 \mu \mathrm{m})$. The electrolytic corrosion polishing equipment was DFP-2, as shown in the Fig. 6(b). The electrolytic polishing liquid was $\mathrm{CH}_{3} \mathrm{OH}$ and $\mathrm{HNO}_{3}\left(\mathrm{CH}_{3} \mathrm{OH}: \mathrm{HNO}_{3}=2: 1\right)$. The specific parameters of the electro polishing were: voltage $20 \mathrm{~V}$, current $5 \mathrm{~A}$. Polishing temperature was the environment temperature $\left(25^{\circ} \mathrm{C}\right)$.

\section{Results and discussion}

\subsection{Residual stress distribution of experiment}

The milling sequence and the residual stress distribution in the feed direction beneath the surface are given in Fig. 8. Fig. 9 shows that the distribution of residual stress beneath the machined surface presented a spoon-shaped pattern. The residual tensile stress on the machined surface was less in the feed direction than perpendicular to the feed direction. Table 4 shows that the residual stress of the compression valley was less in the feed direction than perpendicular to the feed direction. The thickness of RSIL was between 80 to $100 \mu \mathrm{m}$ before milling. The thickness of RSIL was also between 80 to $100 \mu \mathrm{m}$ in the first step milling $\left(a_{e}=0.3 \mathrm{~mm}\right)$.

It was observed from Figs. $9(a)$ and $(c)$ that the compressive residual stress value of the compression valley became smaller in the second step milling $\left(a_{e}=0.3+0.02 \mathrm{~mm}\right.$ and $a_{e}=0.3+0.05$ $\mathrm{mm}$ ), The compression valley shifted to the machined surface (area 2), and the residual stress on the machined surface moved in the direction of tensile stress (area 1). As shown in Fig. 9(b), when the depth of cut was $a_{e}=0.3+0.02 \mathrm{~mm}$ in the second step milling, the residual stress distribution curve was shifted to the right by $0.02 \mathrm{~mm}$. It could be seen from the curve slope trend that the residual stress distribution was only significantly affected within the range of 0.02 to $0.045 \mathrm{~mm}$. Area 1 to 3 in Fig. 
9 (a) presented that RSIL became smaller. The thickness of RSIL was between 60 to $80 \mu \mathrm{m}$. As shown in Fig. 10, the reason for this phenomenon was that the thickness of RSIL in the current step milling was affected by the depth of cut and the thickness of the previous step. When the depth of cut $b$ in the second step milling was less than the thickness of RSIL, the contact area between the tool and the workpiece was reduced, resulting in a smaller cutting force. The cutting force became smaller, so the plastic deformation on the workpiece surface was reduced. The reduction of mechanical stress effect led to the decrease of RSIL. As shown in Fig. $9(d)$, when the depth of cut in the second step milling was $a_{e}=0.3+0.05 \mathrm{~mm}$, the residual stress distribution curve in depth was shifted to the right by $0.05 \mathrm{~mm}$. It could be seen from the curve slope trend that the residual stress distribution was significantly affected within the range of 0.05 to $0.1 \mathrm{~mm}$.

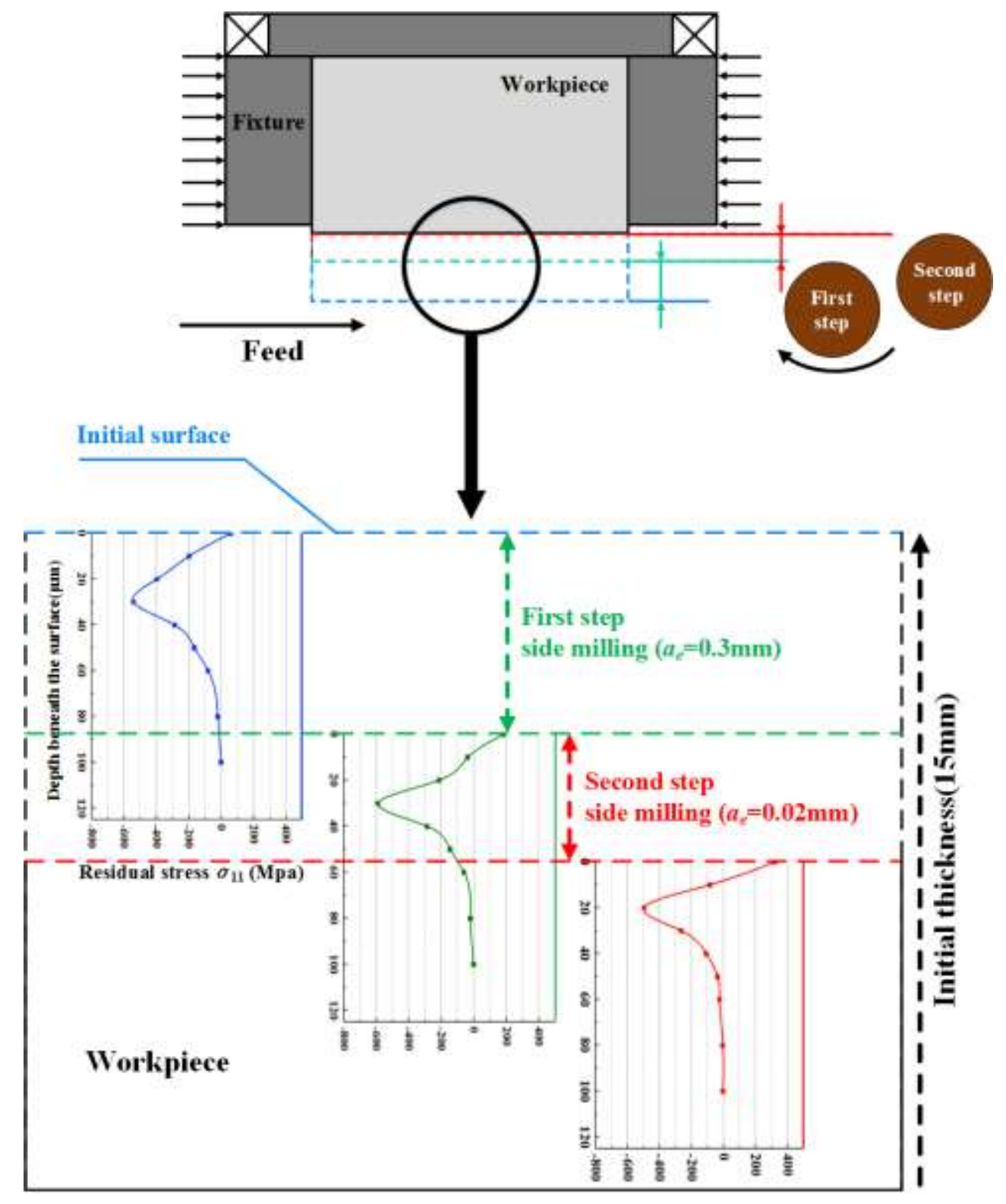

Fig. 8. The milling sequence and the residual stress distribution in the feed direction beneath the surface. 
Table4. Residual stress value of machined surface and compression valley.

No.

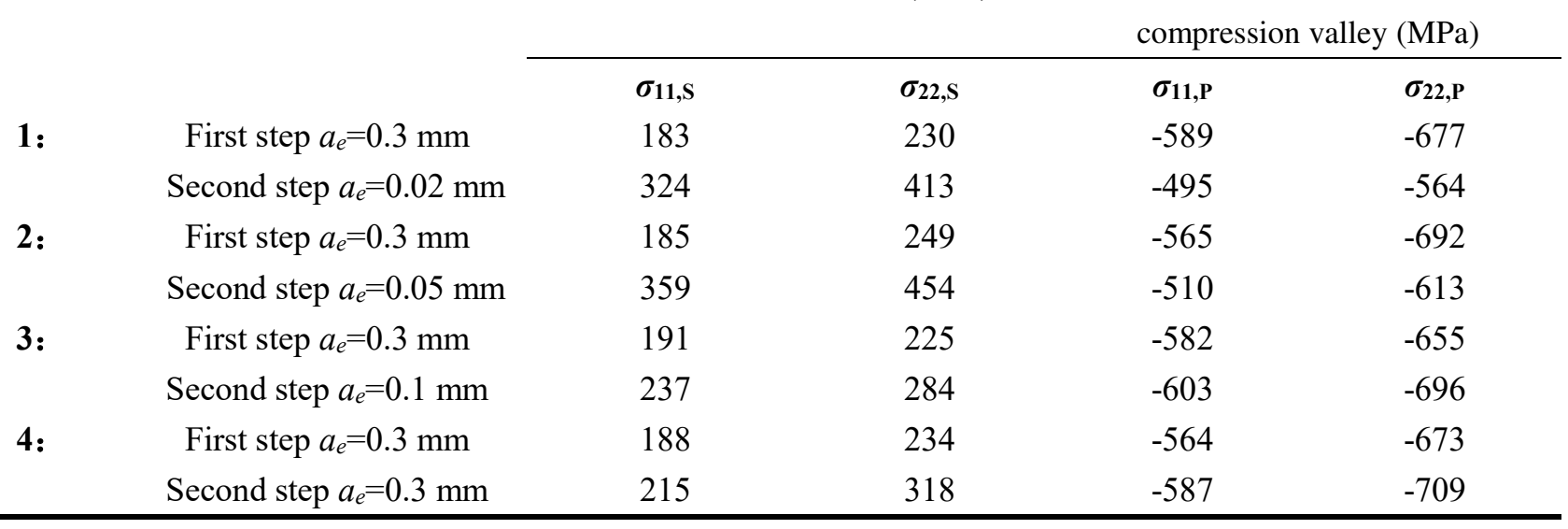

As shown in Fig. $9(i)$ and $(k)$, when the depths of cut were $a_{e}=0.3+0.1 \mathrm{~mm}$ and $a_{e}=0.3+0.3 \mathrm{~mm}$ in the second step milling, the compressive residual stress value of the compression valley and the tensile stress value of the machined surface were increase. The increase of the stress value was small. The depths of the compression valley from the machined surface were about $30 \mu \mathrm{m}$. The thickness of RSIL in the first step was the same as in the second step. The thickness of RSIL was still between 80 to $100 \mu \mathrm{m}$. The reason for this phenomenon was that when the depth of cut was greater than the thickness of RSIL, the residual stress distribution in the previous step had almost no effect on stress distribution in the current step. The small increase in the stress value of the machined surface was caused by the accumulation of the thermal loads in the side milling.

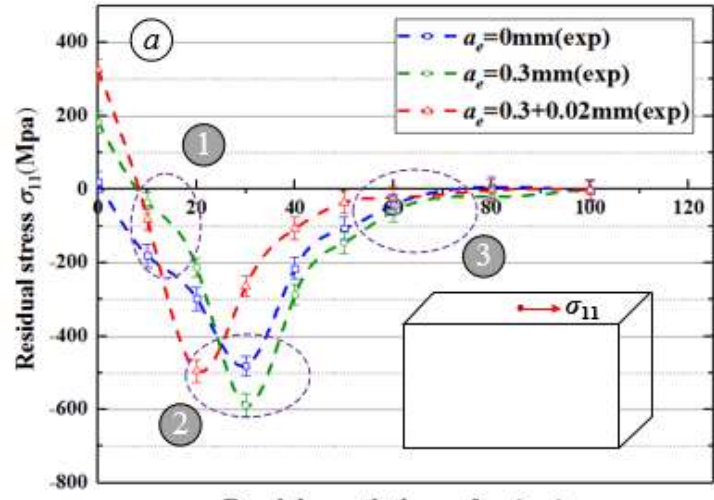

Depth beneath the surface $(\mu \mathrm{m})$

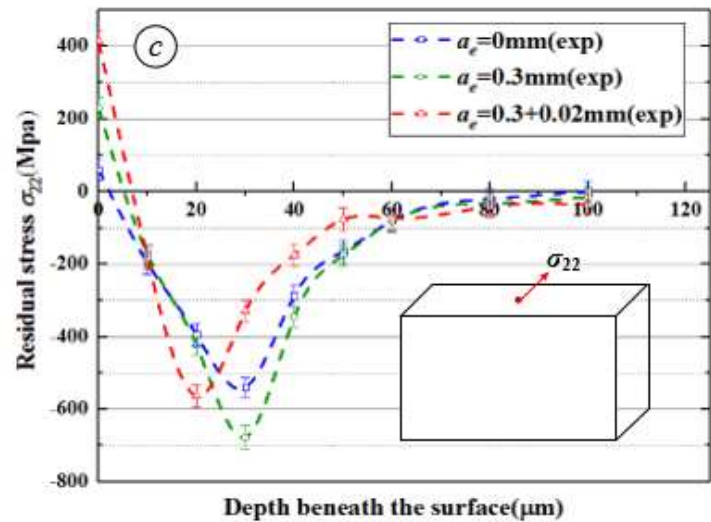

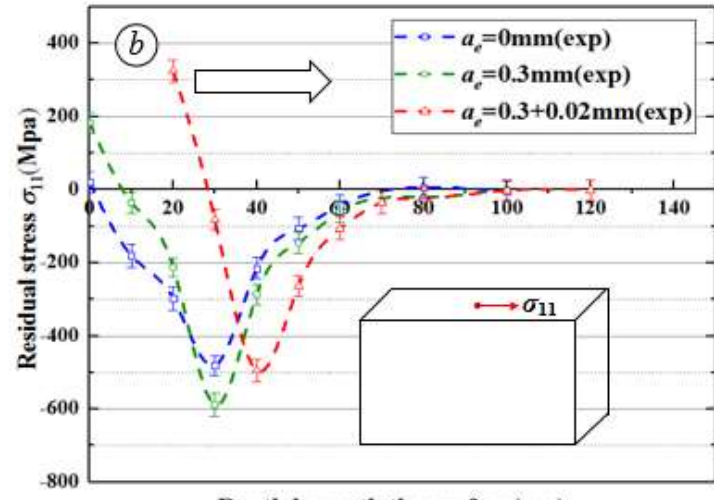

Depth beneath the surface $(\mu \mathrm{m})$

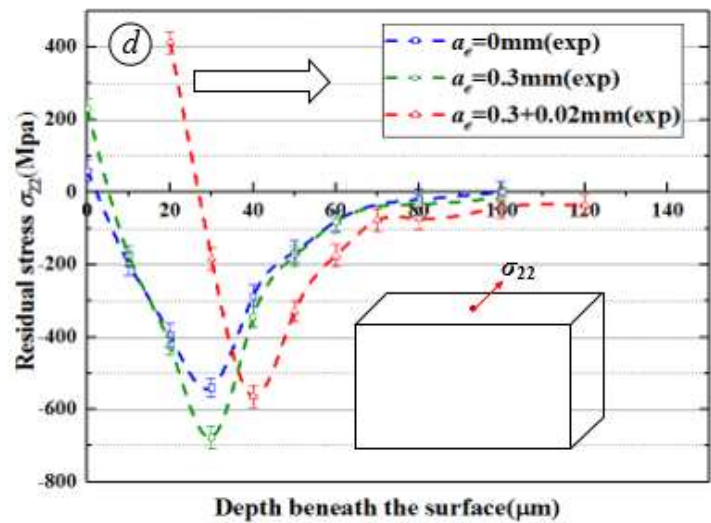



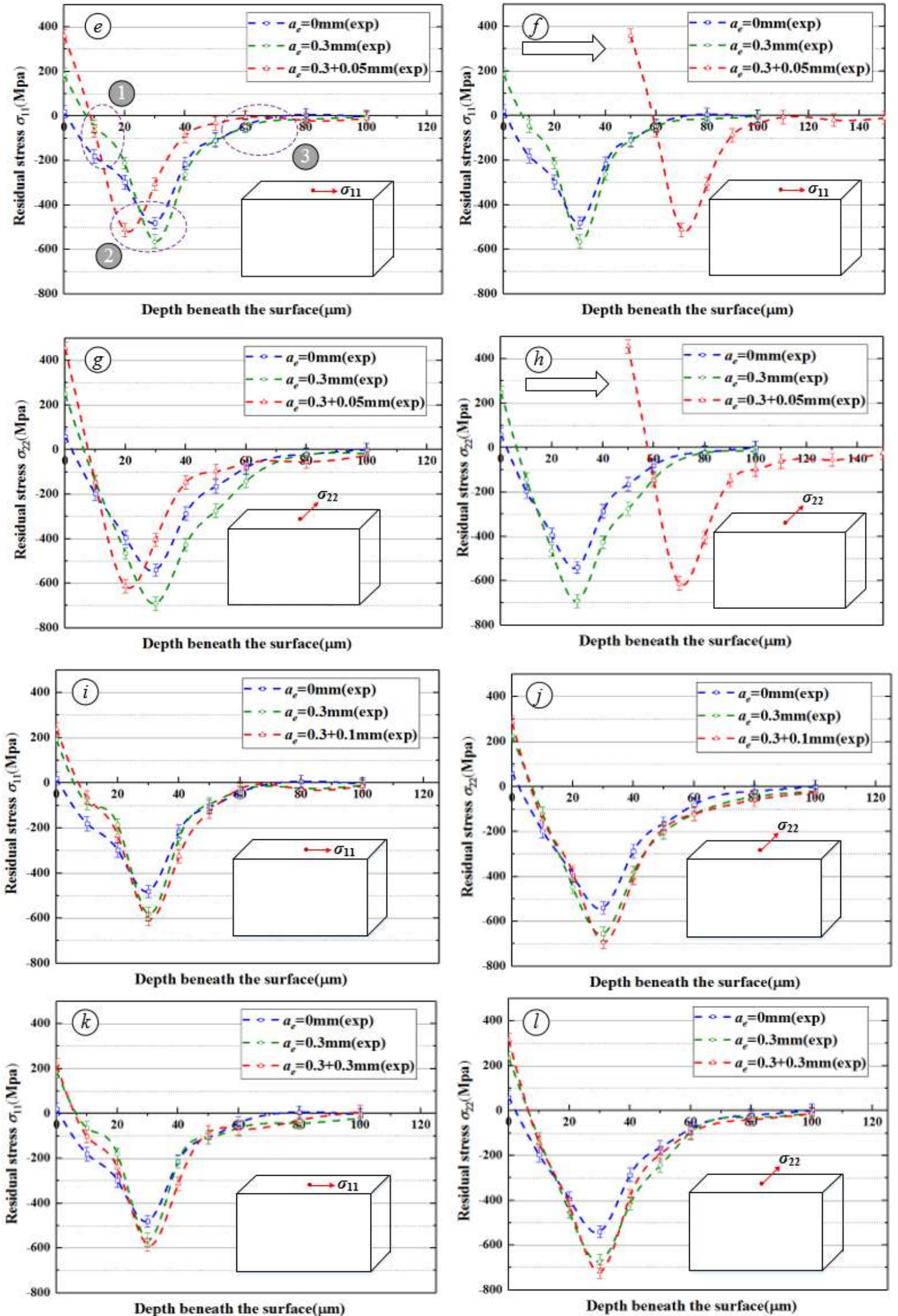

Fig. 9. Residual stress distribution beneath the machined surface of the sequential side milling GH4169. 

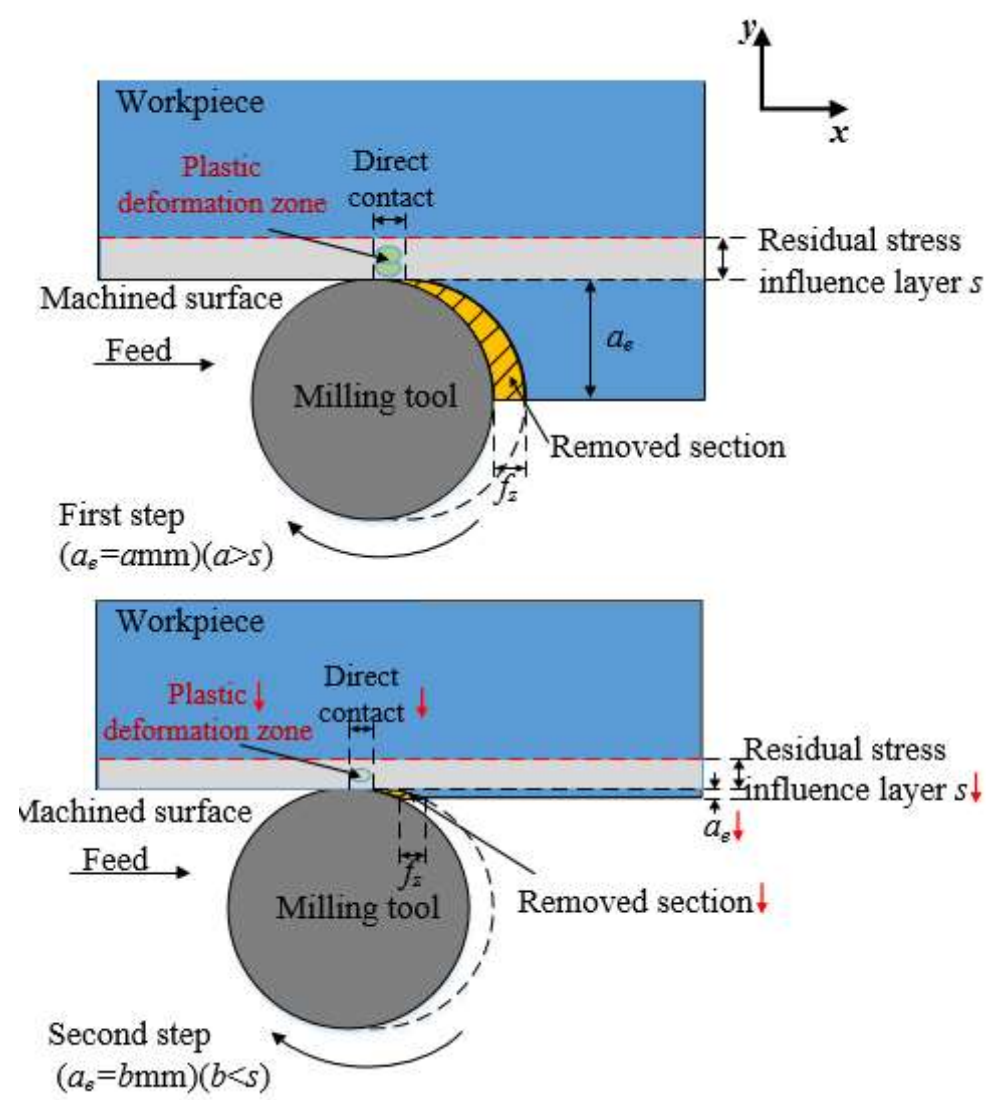

Fig. 10. Influence of radial depth of cut in the side milling on the thickness of residual stress influence layer.

\subsection{Residual stress distribution of simulation}

The simulation residual stress distribution curve (shown in Fig. 11) was drawn according to the drawing method of the experimental residual stress distribution. The depth of the compression valley in the first and second steps milling was at $22 \mu \mathrm{m}$ from the machined surface. When the depth of cut was $a_{e}=0.3+0.1 \mathrm{~mm}$, the residual stress of the compression valley was reduced by $52 \mathrm{MPa}$ compared with $a_{e}=0.3 \mathrm{~mm}$. The tensile stress of the machined surface was increased by $43 \mathrm{MPa}$. The residual stress distribution curve of $a_{e}=0.3+0.3 \mathrm{~mm}$ and $a_{e}=0.3 \mathrm{~mm}$ almost coincided. This simulation result could verify the conclusion drawn by the experimental part because the RSIL was smaller than the depth of cut and there was almost no interaction between the residual stress distributions of the two steps. 

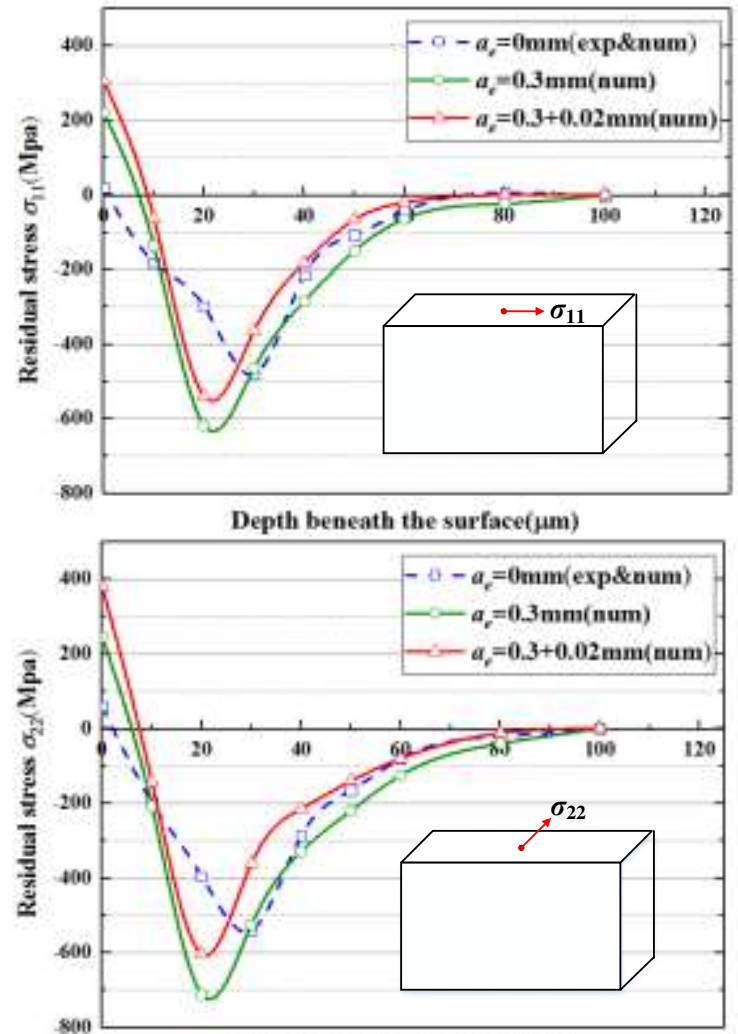

Depth beneath the surface $(\mu \mathrm{m})$
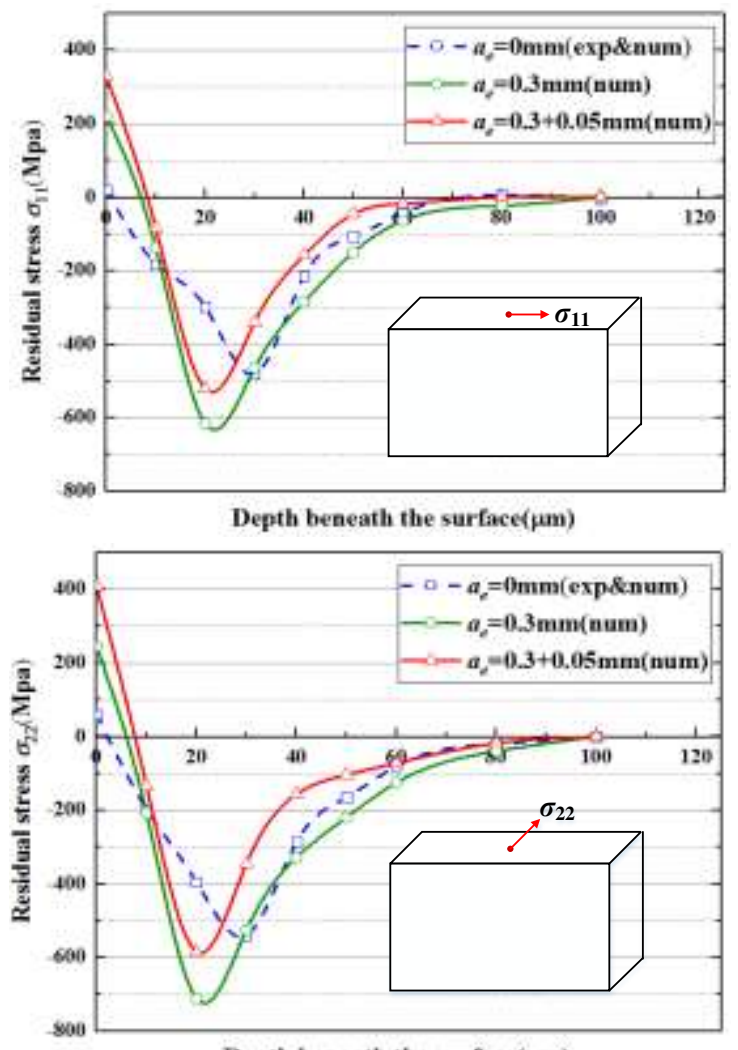

Depth beneath the surface $(\mu \mathrm{m})$
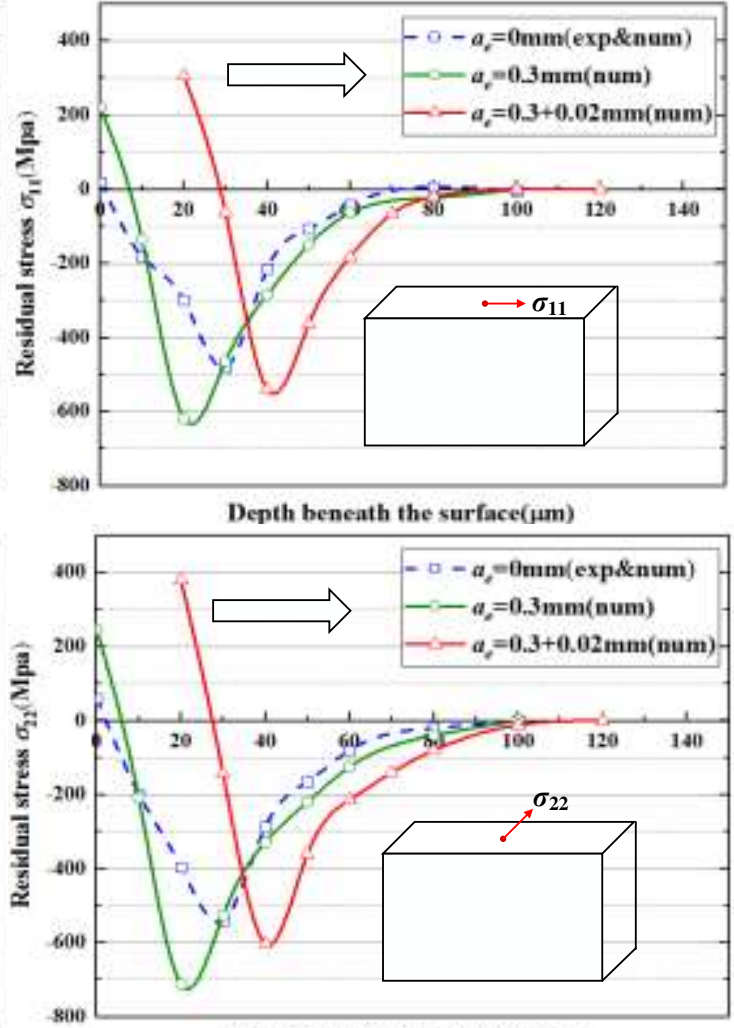

Depth beneath the surface $(\mu \mathrm{m})$
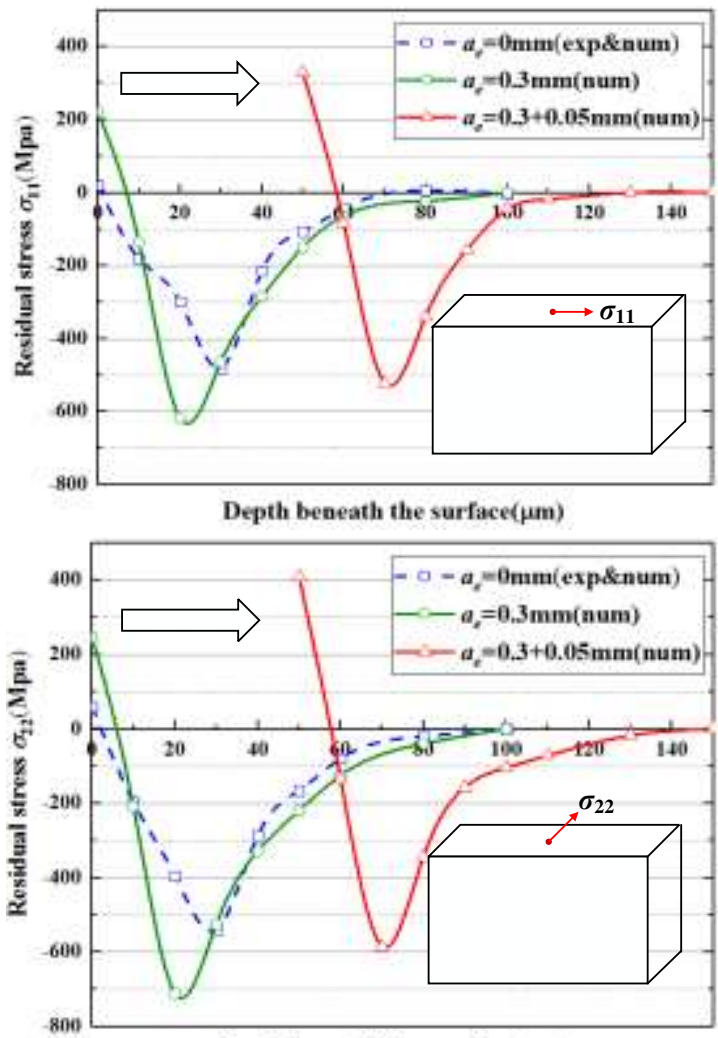

Depth beneath the surface( $\mu \mathrm{m})$ 

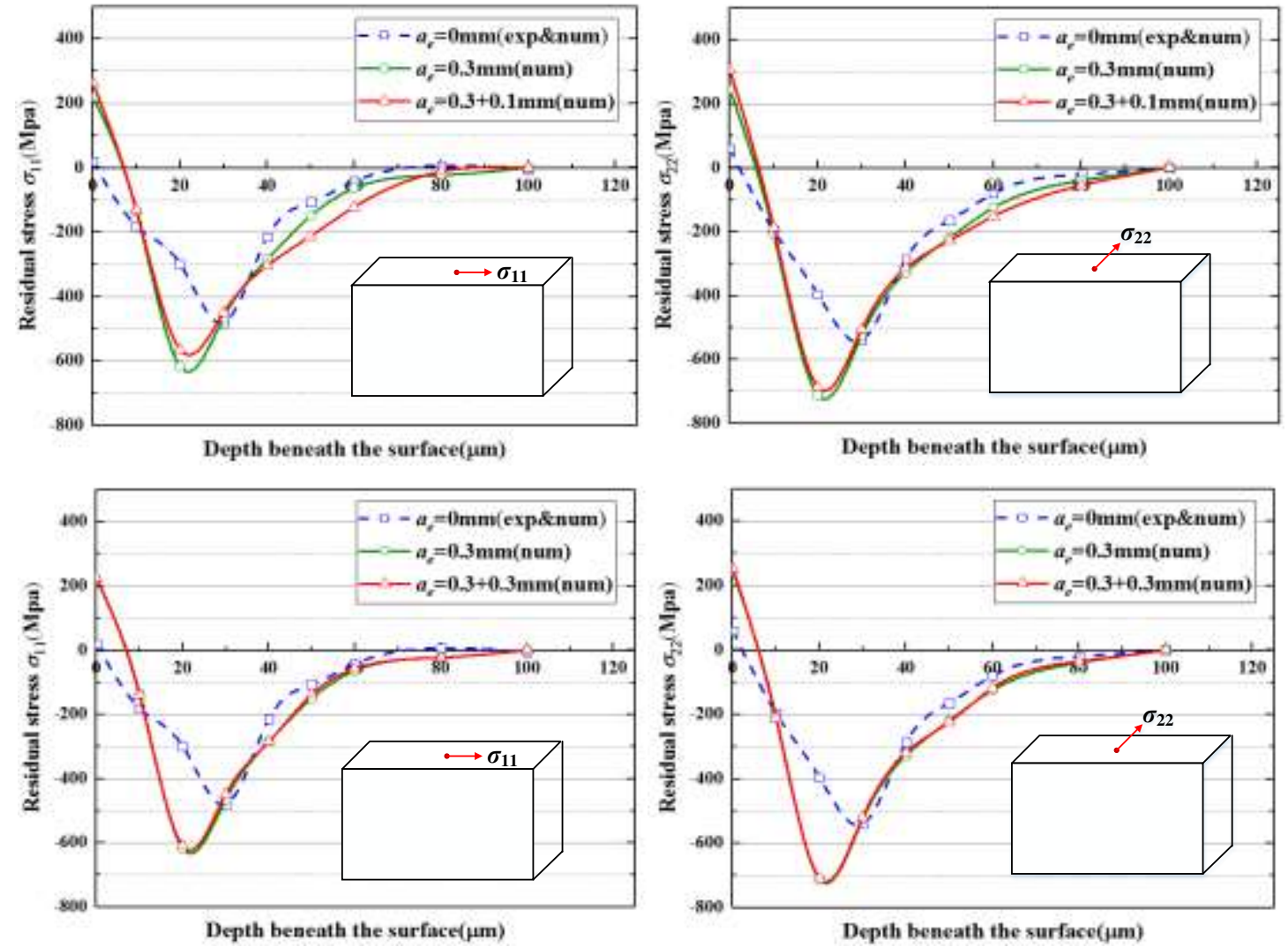

Fig. 11. Residual stress distribution beneath the machined surface of the s side milling GH4169 simulation.

\subsection{Comparison of residual stress between simulation and experiment}

A comparison of residual stress distributions of the experiment with simulation is given in Fig. 12. When the depth of cut was $a_{e}=0.3 \mathrm{~mm}$ in the first step milling, the depth of residual stress compression valley in the simulation model was at $22 \mu \mathrm{m}$ from the machined surface. The depth of residual stress compression valley in the experiment was at $30 \mu \mathrm{m}$ from the machined surface. The residual stress values of machined surface and compressed valley were in good agreement between experiment and simulation.
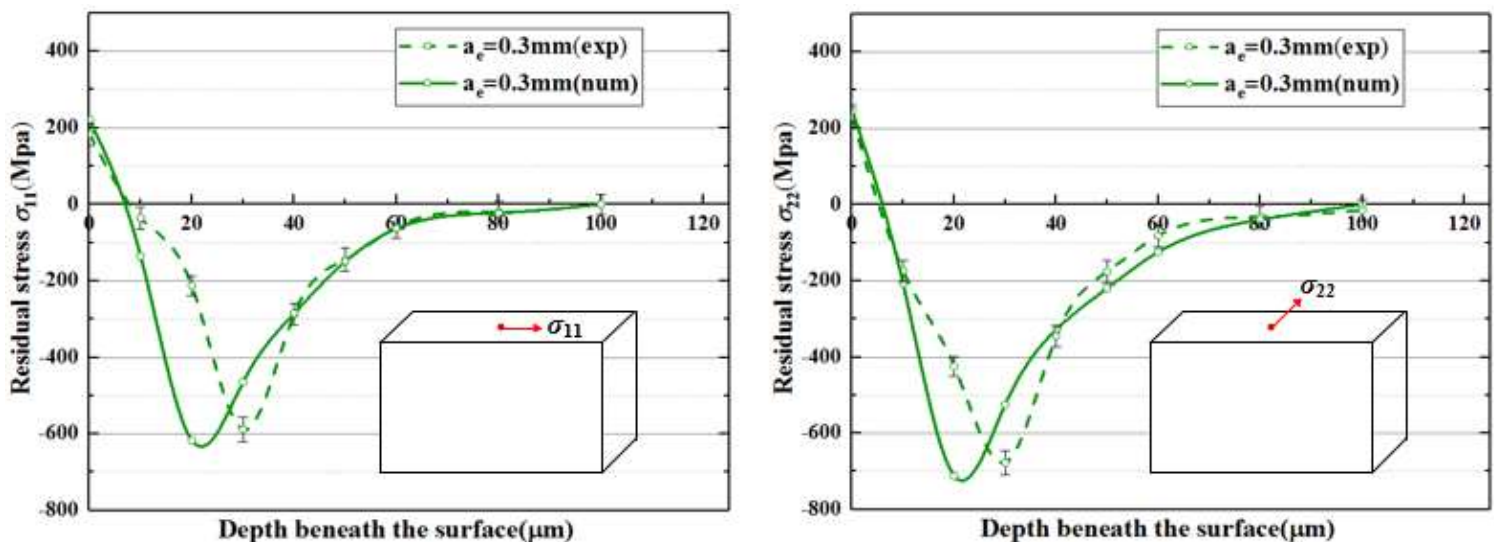

Depth beneath the surface $(\mu \mathrm{m})$ 

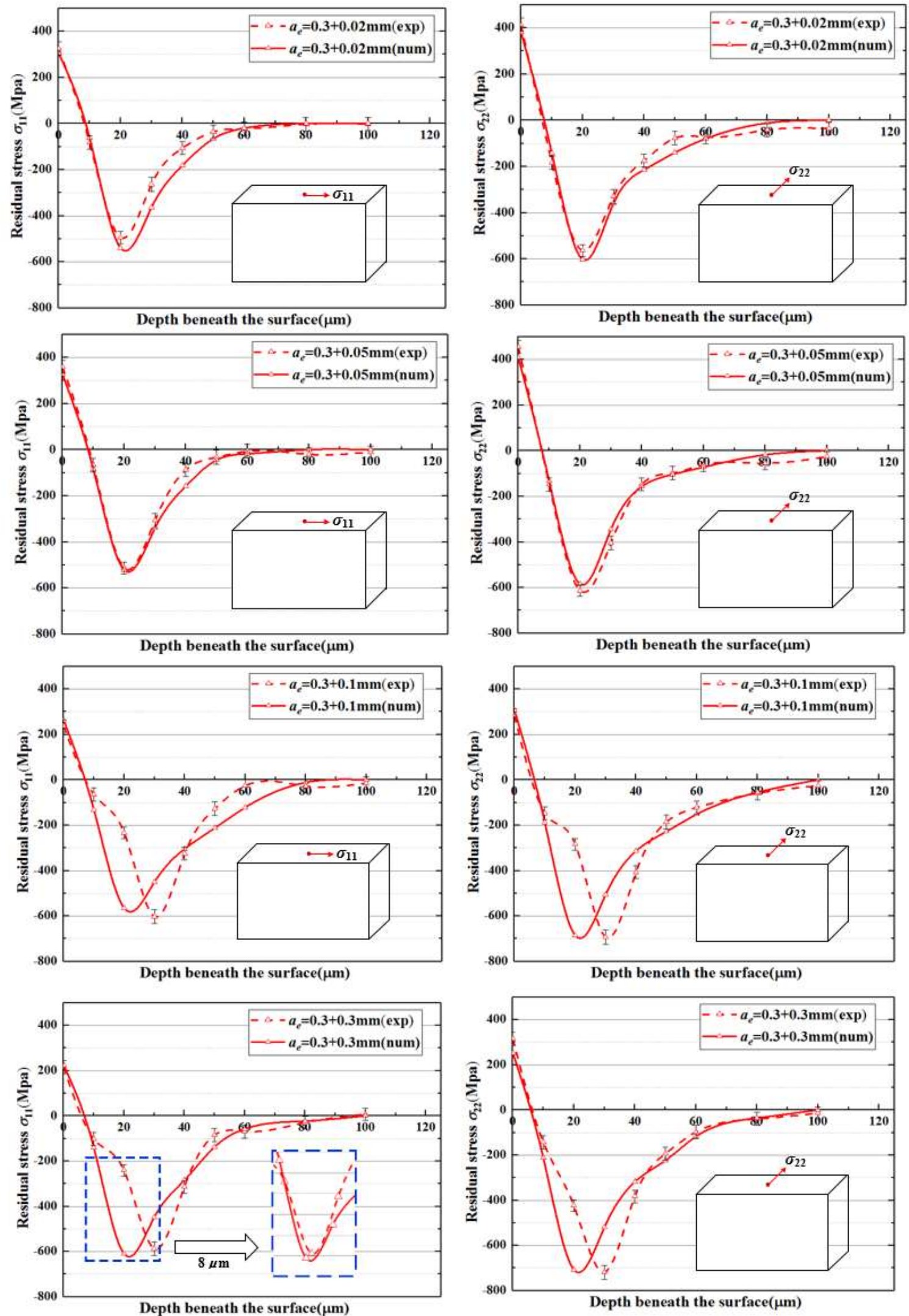

Fig. 12. Comparison of residual stress distribution between experiment and simulation.

When the depths of cut were $a_{e}=0.3+0.02 \mathrm{~mm}$ and $a_{e}=0.3+0.05 \mathrm{~mm}$ in the second step milling, the depths of residual stress compression valley in the simulation and experiment were both at $22 \mu \mathrm{m}$ from the machined surface. The residual stress values of the machined surface and compressed valley 
were in good agreement between experiment and simulation. The difference between experimental and simulation values was generally less than $60 \mathrm{MPa}$. The distribution of residual stress in depth was highly consistent between the experiment and simulation.

When the depth of cut was $a_{e}=0.3+0.1 \mathrm{~mm}$ and $a_{e}=0.3+0.3 \mathrm{~mm}$ in the second step milling, the depth of residual stress compression valley in the simulation model was $22 \mu \mathrm{m}$ from the machined surface. The depth of the residual stress compression valley in the experiment was at $30 \mu \mathrm{m}$ from the machined surface. The residual stress values of the machined surface and compressed valley were in good agreement between experiment and simulation values. There was a difference between the prediction of the residual stress values at 20-40 $\mu \mathrm{m}$ from the machined surface between the experiment and the simulation. The difference was mainly caused by the location of the simulated compression valley. If the residual stress distribution curve of the simulated model was shifted $8 \mu \mathrm{m}$ to the right, it could be found that the curve also had a strong consistency between the experiment and the simulation. Compared with the experimental values, the average deviation of the residual tensile stress on the machined surface in the sequential simulation model was $7.2 \%$. The prediction accuracy of the model was $92.8 \%$. The prediction accuracy in the proposed model was higher than in Dehmani's model [8]. In summary, the proposed model provided high prediction accuracy of the residual stress in sequential milling.

\section{Conclusion}

A numerical model for predicting the machined surface residual stress in sequential side milling GH4169 considering initial stress was proposed in this research. The experimental investigations of sequential side milling GH4169 were conducted for the purpose of verifying the model prediction results. According to the experiment and simulation results, the following conclusions can be drawn:

1. The surface residual tensile stress and compressive valley stress in the feed direction were less than perpendicular to the feed direction. The distribution of the residual stress in the depth direction from the surface presented a spoon-shaped pattern. When the depth of cut in the second-step milling was smaller than the thickness of RSIL, the compressive stress value of the compression valley became smaller. The compression valley shifted to the machined surface, and the machined surface residual stress moved in the direction of tensile stress.

2. The thickness of RSIL in the current step was affected by the depth of cut of the current step and the thickness of RSIL in the previous step. When the depth of cut was greater than the thickness 
of RSIL, the residual stress distribution of the previous step had little effect on the current step. On the contrary, when the depth of cut was less than the thickness of RSIL in the previous step, the contact area between the tool and the workpiece was reduced, resulting in a smaller cutting force. The cutting force became smaller, so the plastic deformation on the workpiece surface was reduced. The reduction of mechanical stress effect led to the decrease of RSIL.

3. The proposed simulation model was highly consistent with the experimental conclusions. This model could make a good prediction of the stress value of the machined surface and the compression valley, and the residual stress distribution in depth beneath the machined surface of the sequential side milling. The prediction accuracy of this model was $92.8 \%$. This model could predict the thickness of RSIL and optimize the depth of cut of the design sequential side milling.

\section{Availability of data and materials}

All data and materials used or analyzed during the current study are included in this manuscript.

Authors' contributions

Gonghou Yao: Methodology, investigation, formal analysis and writing draft. Zhanqiang Liu: Project administration, formal analysis, review and editing. Qinghua Song: Supervision, review and editing. Bing Wang: Supervision. Yukui Cai: Review.

\section{Funding}

The authors would like to acknowledge the financial support from the National Key Research and Development Program of China (2019YFB2005401). This work was also supported by grants from the National Natural Science Foundation of China (No. 91860207) and Taishan Scholar Foundation.

\section{Declarations}

\section{Ethical Approval}

The manuscript is approved by all authors for publication. The authors declare that they have no conflict of interest. This manuscript is original and the entire paper nor any part of its content has never been published in other journals. The data and results are true and clear. We guarantee the transparency and objectivity of research, and strictly abide by the ethical and professional standards of the industry.

\section{Consent to participate}

All the authors listed agree to participate in this manuscript.

\section{Consent to publish}

All co-authors agree to publish the version of this work in The International Journal of Advanced Manufacturing Technology.

\section{Competing Interests}

The authors declare that they have no conflict of interest.

\section{References}

[1] Thakur A, Gangopadhyay S (2016) State-of-the-art in surface integrity in machining of nickel-based super 
alloys. Int J Mach Tool Manu 100:25-54. https://doi.org/10.1016/j.ijmachtools.2015.10.001.

[2] Ulutan D, Ozel T (2011) Machining induced surface integrity in titanium and nickel alloys: A review. Int J Mach Tool Manu 51:250-280. https://doi.org/10.1016/j.ijmachtools.2010.11.003.

[3] Withers P J, Bhadeshia H (2001) Residual stress. Part 1-measurement techniques. Mater Sci Tech-Lond 17:355-365. https://doi.org/10.1179/026708301101509980.

[4] Withers P J, Bhadeshia H (2001) Residual stress. Part 2-Nature and origins. Mater Sci Tech-Lond 17:366-375. https://doi.org/10.1179/026708301101510087.

[5] Huang Q, Ren J X (1991) Surface integrity and its effects on the fatigue life of the nickel-based superalloy GH33A. Int J Fatigue 13:322-326. https://doi.org/10.1016/0142-1123(91)90359-7.

[6] Jafarian F, Amirabadi H, Sadri J (2015) Experimental measurement and optimization of tensile residu al stress in turning process of Inconel718 superalloy. Measurement 63:1-10. https://doi.org/10.1016/j. measurement.2014.11.021.

[7] Karabelchtchikova O, Rivero I V (2005) Variability of residual stresses and superposition effect in multipass grinding of high-carbon high-chromium steel. J Mater Eng Perform 14:50-60. https://doi.org/10.1361/10599490522266.

[8] Dehmani H, Salvatore F, Hamdi H (2013) Numerical study of residual stress induced by multi-steps orthogonal cutting. Procedia CIRP 8:299-304. https://doi.org/10.1016/j.procir.2013.06.106.

[9] Grochała D, Berczyński S, Grządziel Z (2014) Stress in the surface layer of objects burnished after milling. Int J Adv Manuf Tech 72:1655-1663. https://doi.org/10.1007/s00170-014-5775-x.

[10] Fergani O, Jiang X, Shao Y, Welo T, Yang J, Liang S (2016) Prediction of residual stress regeneration in multipass milling. Int J Adv Manuf Tech 83:1153-1160. https://doi.org/10.1007/s00170-015-7464-9.

[11] Ma Y, Zhang J, Feng P, Yu D, Xu C (2018) Study on the evolution of residual stress in successive machining process. Int J Adv Manuf Tech 96:1025-1034. https://doi.org/10.1007/s00170-017-1542-0.

[12] Singla S, Kumar V S, Rathinam K, Sharma V (2020) Numerical study of residual stresses in duplex turning process. Materials Today: Proceedings 26:247-255. https://doi.org/10.1016/j.matpr.2019.11.110.

[13] Feng Y, Pan Z, Lu X, Liang S (2018) Analytical and Numerical Predictions of Machining-Induced Residual Stress in Milling of Inconel 718 Considering Dynamic Recrystallization. ASME 2018 13th International Manufacturing Science and Engineering Conference. American Society of Mechanical Engineers Digital Collection 2018. https://doi.org/ 10.1115/MSEC2018-6386.

[14] Shen Q, Liu Z, Hua Y, Zhao J, Lv W (2018) Effects of cutting edge microgeometry on residual stress in orthogonal cutting of Inconel 718 by FEM. Materials 11:1015. https://doi.org/10.3390/ma11061015. 
[15] Uhlmann E, Von Der Schulenburg M G, Zettier R (2007) Finite element modeling and cutting simulation of Inconel 718. CIRP annals 56:61-64. https://doi.org/10.1016/j.cirp.2007.05.017.

[16] Hua Y, Liu Z (2019) Effects of Machining Induced Residual Shear and Normal Stresses on Fatigue Life and Stress Intensity Factor of Inconel 718. Appl Sci-Basel 9:4750. https://doi.org/10.3390/app9224750. 